\title{
Research and Application of Control Strategy Based on Low Nitrogen Combustion
}

\author{
Li Jun \\ Grid Technology Center \\ State Grid Shandong Electric Power Research Institute \\ Jinan, China \\ lijun_sdu@hotmail.com
}

\author{
Li Weiwei \\ Network Center \\ Shandong University of Arts \\ Jinan, China \\ liweiwei@sdca.edu.cn
}

\begin{abstract}
The mechanism of NOx formation, NOx control methods and low nitrogen combustion technologies is to be introduced. Optimization methods such as the optimum excess air coefficient adjustment test, the combination of unit load and burner, secondary air distribution mode have been proposed. Actual operating results show that optimization methods can ensure boiler thermal efficiency, boiler flue gas heat loss and physical incomplete combustion loss is essentially the same compared with the past and achieve nitrogen oxide requirements of environmental standards.
\end{abstract}

Keywords-staging combustion; low nitrogen combustion; excess air coefficient; air distribution; heat loss

\section{INTRODUCTION}

Nitrogen oxides in the atmosphere primarily come from industrial pollution, traffic pollution and domestic pollution. In China, about $65 \%$ of $\mathrm{NOx}$ is produced by pulverized coal combustion, and the NOx released from pulverized coal boilers accounts for about $80 \%$ of $\mathrm{NOx}$ produced by pulverized coal combustion. The total NOx emissions of coal-fired power plants in China is growing year by year, therefore, it is a very urgent task to reduce the NOx emissions of coal-fired boilers. Emission standard of air pollutants for thermal power plants of China explicitly stipulate, from July 2014, the three most important emissions targets of power plant that $\mathrm{SO}_{2}, \mathrm{NOx}$, dust emission concentrations were controlled within $100 \mathrm{mg} / \mathrm{m}^{3}, 100 \mathrm{mg} / \mathrm{m}^{3}$ and $30 \mathrm{mg} / \mathrm{m}^{3}$, far lower than the current European and American respectively $200 \mathrm{mg} / \mathrm{m}^{3}$, $200 \mathrm{mg} / \mathrm{m}^{3}$ and $30 \mathrm{mg} / \mathrm{m}^{3}$ emission standards. After the implementation of the new standard, to 2015, the power industry can reduce 6.18 million tons of $\mathrm{SO}_{2}$ emissions, NOx emissions can be reduced 5.8 million tons.

The transformations of NOx mainly take two technologies, low nitrogen burner and SCR denitration. Up to now, by the research of unit transformation, we can find that unit's combustion significantly lengthen the time after the transformation of low nitrogen burner. It causes the main steam pressure and the main steam temperature etc. parameters of unit fluctuated, and affect the control quality of unit's load. Therefore, effective control measures taken to reduce the impact on unit load control are an urgent demand for power plants and the grid.

\section{CHARACTERISTIC ANALYSIS OF $\mathrm{NO}_{x}$}

According to the mechanism of the boiler flue gas to generate nitrogen oxides, the factors that affect the generation amount of nitrogen oxide compounds mainly the flame temperature, the oxygen concentration in the burner zone, the residence time of combustion products in the high temperature zone and the coal properties. There are two main ways that reduce the amount of nitrogen oxides generated: reduce flame temperature and prevent local temperature, reduce excess air ratio and oxygen concentration, ensure pulverized coal combustion under hypoxic conditions.

In the various techniques for reducing NOx emissions, low nitrogen combustion technology the most widely used, relatively simple, economic and effective. At present, there are basically have the following several types, low excess air combustion, pulverized coal staging combustion and flue gas recirculation[1, 2]. The pulverized combustion is currently the most widely used low nitrogen combustion technology[3]. Its main principle is part of the air needed for combustion, commonly known as the separate over fire air (SOFA), to feed into the furnace from its upper region, form a reduction zone between the main burner and the SOFA, it is shown in Fig. 1. It can inhibit the generation of NOx and reduce the generated NOx, reduce boiler NOx emissions.

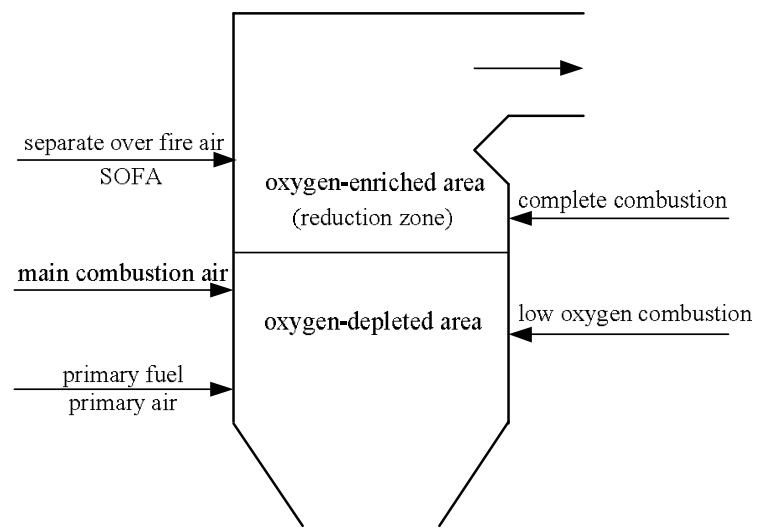

Figure 1. Schematic diagram of staging combustion.

By using pulverized coal staging combustion of low nitrogen technology, the temperature field distribution of furnace will be changed greatly, mainly shown as the main combustion zone temperature decreases and the flame center shift[4].

A large amount of NOx generate in the main combustion zone before transformation, when the flue gas pass through the original OFA, the concentration of NOx 


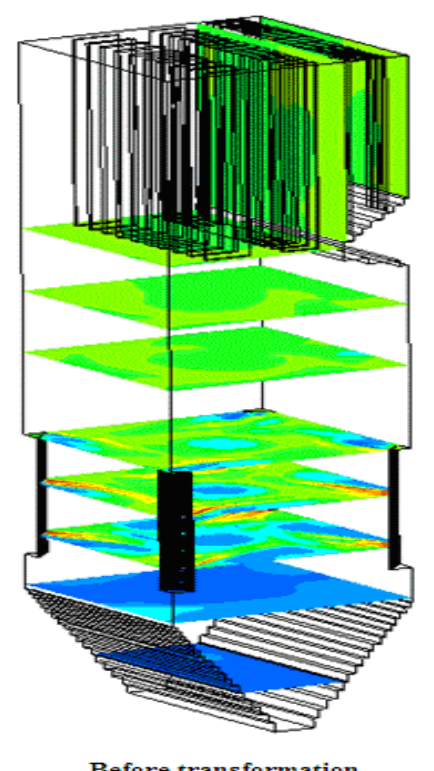

Before transformation

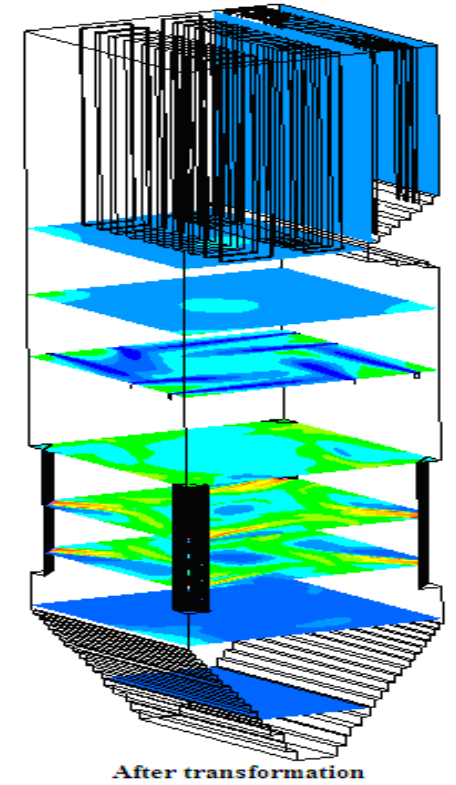

After transformation

Figure 2. The comparation of NOx concentration before and after transformation.

is basically unchanged. After the transformation, although in the main combustion zone has generated a lot of NOx, but due to reduced oxygen concentration in the main combustion zone, an oxidizing atmosphere weakened, and the wind due to SOFA, the concentration of NOx in the furnace at the exit decreased very significantly. The comparation of NOx concentration before and after transformation is shown in Fig.2.

Based on the mechanism of NOx generation, the formation of NOx of large power plant mainly divides into: thermal NOx and fuel NOx. A large number of studies have shown that the thermal NOx and fuel NOx are related to the following factors: as thermal NOx type, when the temperature higher than $1500^{\circ} \mathrm{C}$, NO generation of exponential law of rapid growth, the longer the residence time at high temperature, oxygen concentration, the greater the availability of NO generation. As NOx fuel type, fuel nitrogen content is higher, the excess air coefficient, the greater the fuel type of NOx generation, and the higher conversion rate.

Look from the thermal type and fuel type mechanism of NOx formation, to reduce NOx, should take the following measures, to reduce thermal NOx, requires low oxygen concentration and low temperature, short staying time in high temperature. Reducing fuel type NOx, low oxygen requirements, especially volatile precipitation and combustion stage, the amount of oxygen as low as possible From the above analysis, we can see that technical measures to reduce NOx emissions to a certain extent, and stable combustion, reducing fuel ash, slagging and reduce temperature to prevent corrosion in contradiction. So, using technical measures to reduce NOx emissions should be considered. In the combustion, slagging and high temperature corrosion is often occurred, thorough understanding and analysis to develop practical technical solutions.

\section{OPERATION ANALYSIS}

In many power plants with low nitrogen burner transformation, steam temperature (especially reheat steam temperature) is generally low and the fly ash combustible is big. After the transformation of low nitrogen burners, the change of temperature field in the furnace will affect outlet smoke temperature and steam temperature characteristics[5,6]. Purely from the perspective of burning, after the transformation of low nitrogen combustion, combustion delay, flame center shift, furnace outlet smoke temperature rises, the boiler superheated steam temperature, reheat steam temperature rise.

\section{A. Analysis of oxygen and NOx emmissions relationship}

From the plant running situation of low nitrogen combustion, the use of design coal, with increasing the amount of SOFA, excess air coefficient of the main combustion zone will reduce, the temperature rise of the superheated and reheated steam temperature are increased considerably. Meanwhile, due to the combustion delay, the main steam pressure response is slow in the AGC mode, thereby affect the control precision of the unit's load.

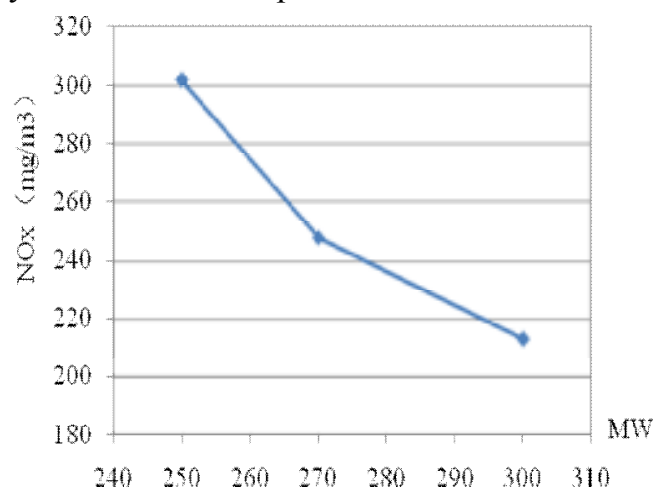

Figure 3. Trend between NOx and load.

A conventional 300MW subcritical drum boiler unit, A, $\mathrm{B}, \mathrm{C}$ three double inlet and outlet mill, each corresponding layer 2 burners, bottom-up A1, A2, B1, B2, C1 and C2 A total of 6 layers. The range of unit load is $250-300 \mathrm{MW}$, if coal quality can be guarantee A, B two milling system operation to meet the needs of the unit-load. Open all the 
OFA, the NOx content of flue gas will remain at 210$300 \mathrm{mg} / \mathrm{m} 3$. The unit load is $260-280 \mathrm{MW}$, the NOx content maintained in $240-280 \mathrm{mg} / \mathrm{m} 3$. The above two conditions, the oxygen content need to maintain in the scope of 3.5$4.0 \%$. The range of unit load is $280 \mathrm{MW}-300 \mathrm{MW}$, the NOx content remain at $210-260 \mathrm{mg} / \mathrm{m} 3$, the oxygen content need to maintain in the scope of $3.0-3.7 \%$. The trend between NOx and load is shown in Fig.3.

If the coal quality deteriorates and A, B, C three milling system operation, all 6 layer burner put into operation all the time, the burnout space narrowing, the NOx content was significantly higher. If the OFA and SOFA fully open, the smoke gas NOx content is about $330-380 \mathrm{mg} / \mathrm{m}^{3}$, serious reached $400 \mathrm{mg} / \mathrm{m}^{3}$ or more. According to the operating adjustments, the NOx content of flue gas is very sensitive to oxygen. NOx content under the load of $240 \mathrm{MW}$, oxygen amounted to about $4.0 \%$, NOx content is higher and it will rise to $360 \mathrm{mg} / \mathrm{m}^{3}$ or more.

\section{B. Primary air effect on nitrogen oxide emissions}

According to primary air pipe diameter, right pressure of primary air can prevent the pulverized coal deposition in pipe. On the other hand, it also can avoid the pulverized coal ignition too close to the burner. From the perspective of low nitrogen combustion to consider and suggest, whether can in allowed range properly reduce the value of primary air pressure.

According to the combustion theory, pulverized coal ignition temperature decreases with the primary air reduce. Without changing the amount of secondary air ratio, can be slightly delayed after the meeting point of ignition of pulverized coal and secondary air flow, thus making after ignition of pulverized coal in the short run the state of hypoxia, reduced generation of nitrogen oxides content of the fuel type.

Especially for intermediate storage pulverizing system, by reducing primary air pressure to actually relates to the whole problem of the efforts of ventilation in the coal pulverizing system. But while reducing the generation of airflow class to reduce nitrogen oxide content, but decreased after an air volume and field observation of burner nozzle coking effect is obvious.

Coal has a significant impact on NOx emission concentration, in addition to the difference in the characteristics of pollutant emissions from coal itself, more important is the impact of coal combustion characteristics and its combustion equipment.

\section{MEASURES TAKEN}

Because of the combustion characteristics of the coal have a great influence on the outlet NOx emission concentration of boiler outlet[7,8], so, according to coal quality is good or bad, the size of sofa opening can be determined. Coal quality is good, SOFA damper open big points. Coal quality is poor, SOFA damper open a small point.

\section{A. Load distribution and mill start-stop mode test}

According to the load distribution of the burner, the purpose is to change the temperature distribution inside the furnace, in order to solve the flame deflection, slagging, flue gas side heat deviation is too large, steam temperature is high or low, reheater metal overtemperature and thermal economy is poor. Test is to find out the adjustment range of the burner output to determine a reasonable combination of the number of different milling system and burner reasonable under different unit load[9,10]. Adjustment should be phased boiler load test on the scheduled test various combinations itemized.

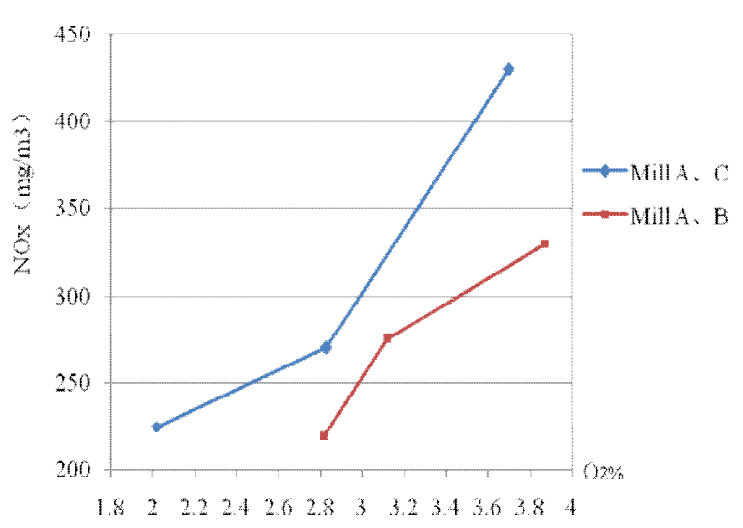

Figure 4. Influence of coal mill operation mode of NOx emission concentratio.

A conventional $300 \mathrm{MW}$ subcritical drum boiler unit, respectively, we take experiments in the boiler operating conditions $\mathrm{A}, \mathrm{C}$ and mill $\mathrm{A}, \mathrm{B}$ mill running. The influence of coal mill operation mode of NOx emission concentration is shown as Fig.4.

TABLE I. NOX EMISSION CONCENTRATION UNDER DIFFERENT COAL MILL OPERATION MODEN

\begin{tabular}{|c|c|c|c|c|}
\hline \multirow{2}{*}{$\begin{array}{c}\text { Unit } \\
\text { Number }\end{array}$} & Load & $\begin{array}{c}\text { Mill } \\
\text { Operation }\end{array}$ & $\begin{array}{c}\text { Export } \\
\text { Oxygen Air } \\
\text { Preheater }\end{array}$ & $\begin{array}{c}\text { NOx } \\
\text { Concentration }\end{array}$ \\
\cline { 2 - 5 } & $\boldsymbol{M W}$ & - & $\boldsymbol{\%}$ & $\boldsymbol{m g} \boldsymbol{m}^{\mathbf{3}}$ \\
\hline 1 & 243 & A、B & 4.46 & 250 \\
\hline 3 & 252 & B、C & 2.85 & 350 \\
\hline 4 & 235 & A、C & 4.41 & 369 \\
\hline
\end{tabular}

As can be seen from Table I indicate that NOx emission concentration that $\mathrm{A}, \mathrm{C}$ mill and $\mathrm{B}, \mathrm{C}$ mill operating conditions was significantly higher than A, B mill operating conditions, mainly because of $\mathrm{A}, \mathrm{B}$ mill is running, A, B mill corresponding burner distance is closer, relatively concentration of pulverized coal is higher, fuelrich region and reducing atmosphere formed at the exit of the burners, will generate the NOx reduction, reduce NOx generation. Therefore, bottom-up mode recommended running the burner in the actual runtime.

\section{B. Excess air coefficient test}

The test should be conducted at selected load and stable coal, at the same time, ensure that the boiler air leakage coefficient within the allowed range. Test should maintain a constant primary air flow and just rely on the change of the total air flow or secondary air flow to adjust the excess air coefficient value of the boiler. In every predetermined test conditions, according to counter balance the requirements of the boiler of the relevant experimental project to measure, record and calculate, 
draw the curve of each loss, and to determine the optimum excess air coefficient.

\section{Air distribution mode}

There are two kinds of secondary air distribution, uniform air distribution and waisted air distribution, shown as in Table II.

TABLE II. VALUES OF DIFFERENT SECONDARY AIR DISTRIBUTION

\begin{tabular}{|c|c|c|c|}
\hline $\begin{array}{c}\text { Air } \\
\text { Distribution }\end{array}$ & $\begin{array}{c}\text { NOx } \\
\text { Content }\end{array}$ & $\begin{array}{c}\text { Fly Ash Carbon } \\
\text { Content }\end{array}$ & $\begin{array}{c}\text { Hot Loss of } \\
\text { Smoke }\end{array}$ \\
\hline- & $\boldsymbol{m g} / \boldsymbol{m 3}$ & $\boldsymbol{\%}$ & $\boldsymbol{\%}$ \\
\hline uniform & 327 & 1.89 & 5.70 \\
\hline waisted & 274 & 1.89 & 5.65 \\
\hline
\end{tabular}

Normal operating conditions are used uniform air distribution. The waisted style is fit for the principle of staging combustion. The oxygen concentration of the main combustion region is reduced, both to reduce the flame temperature of the main combustion zone, inhibit the combination that intermediate product of nitrogen and oxygen, thereby, reduce the generation amount of NOx, so waisted air distribution is the best air distribution mode. Under the same load, using waisted style, NOx emission concentration can be reduced by about $10 \%$.

After optimization of unit control, in the case of load changes, although the total air and total coal fluctuations occurred, but the concentration of NOx emissions in the vicinity around the basic setpoint of outlet NOx, less volatile, achieve good control effect. Actual operating curve is shown in Fig.5.

It fully meets the requirements of environmental control indicators, $\mathrm{NOx}$ emission concentrations were controlled within $100 \mathrm{mg} / \mathrm{m}^{3}$.

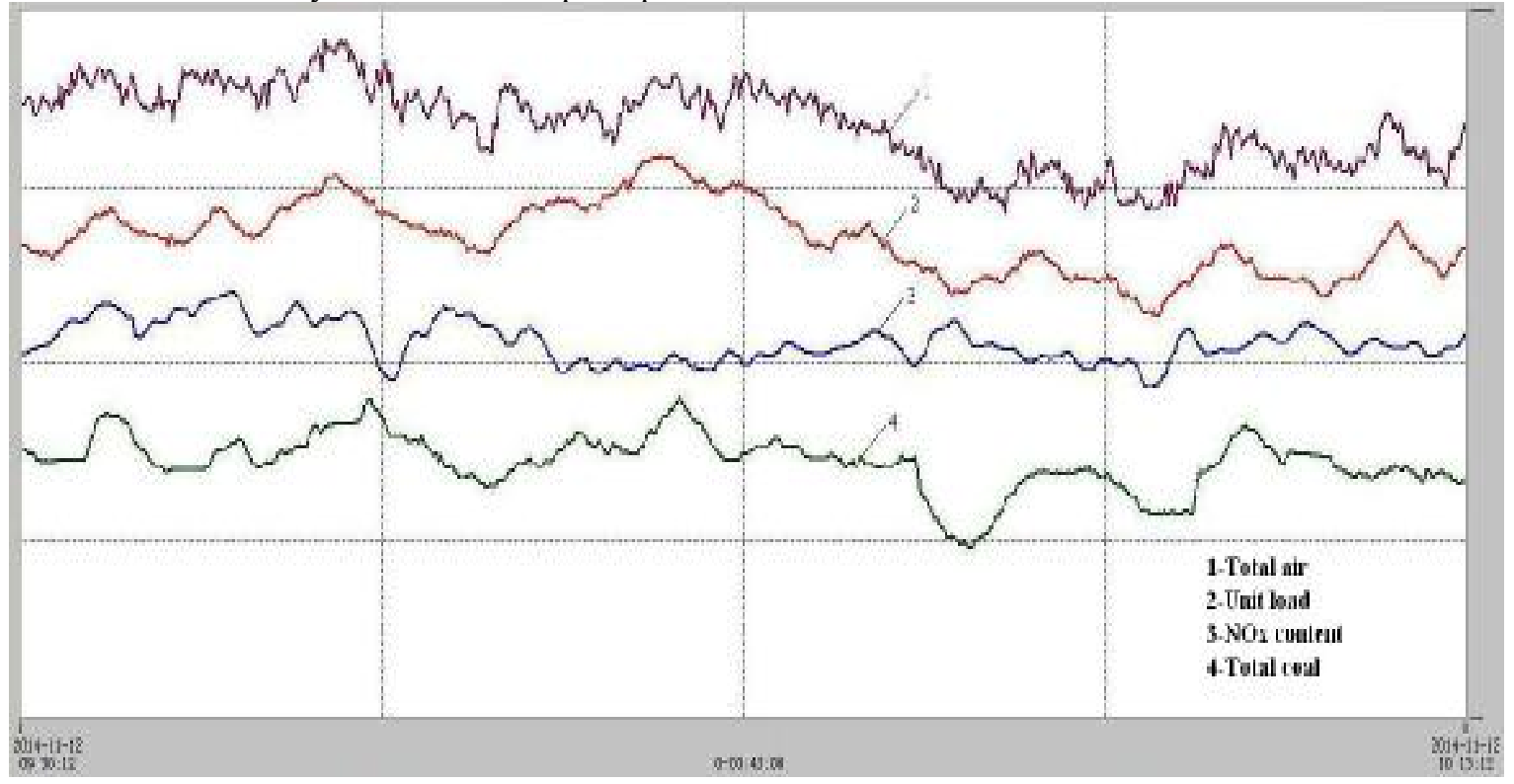

Figure 5. Actual operating curve of unit.

\section{CONCLUSIONS}

By adjusting the excess air coefficient, optimizing the combination of unit load and burner, optimizing secondary air distribution mode, etc., can effectively reduce the concentration of nitrogen oxides emissions, ensure environmental requirements. And compared with the past operating data, boiler flue gas heat loss and physical incomplete combustion loss is essentially the same, so the boiler thermal efficiency broadly unchanged. Optimization control method mentioned in the article, not only can be applied in the same type of subcritical unit and can also be applied in the supercritical unit

\section{REFERENCES}

[1] B.Coda, F.Kluger, D.Fortsch, etc. "Coal-Nitrogen Release and NOx Evolution in Air-Staged Combustion”, Energy \& Fuels, vol. 12, pp.1322-1327, 1998.

[2] Lin Peng-yun, Luo Yong-hao, Hu Li-yuan, "Numerical simulation and analysis of the influencing factors of NOx emissions of coalfired utility boilers", Journal of Engineering for Thermal Energy and Power, vol. 22(5), pp.529-533, 2007.
[3] Kang M., Yeon T. H., Park E. D., Yie J. E.,et al. "Novel MnOx catalysts for NO reduction at low temperature with ammonia", Catalysis Letters, vol. 106(1-2), pp.77-80, 2006.

[4] M.H.Xu, J.L.T.Azevedo, M.G.Carvalho, "Modeling of the Combustion Process and NOx Emmission in a Utility Boiler", Fuel, Vol. 79(13), pp.1611-1619, 2000.

[5] Kurosea R, Makinob H, "Numerical analysis of pulverized coal cumbustion characteristics using advanced low-NOx burner", Fuel, 84, pp.693-703, 2004

[6] D.R.Coyghanowr, Process Systems Analysis and Control, New York: McGraw-Hill, 1991.

[7] Yao Qiang, Chen chao, Technology of clean coal combustion, Beijing: Chemical Industrial Publishing Company, 2005.

[8] J.L.T Azevedo, Coimbra C.F.M and Carvalho M.G., "3-D Numerical Model for Predicting NOx Emssions From an Industrial Pulverized Coal Combustor" , Fuel, vol. 73(7) , pp.1128-1134 1994.

[9] Hu Wei-feng, Xie Jing-mei, "Feasibility study on 600MW boiler low-NOx combustor retrofitting", Electric Power Construction, vol. 30(3) , pp.70-73, 2009.

[10] Jia Hong-lu, "Flow adjustable type burners and low-NOx combustion", East China Electric Power, pp.724- 27, 1992. 